\title{
Exploring experiences of using a case study as a teaching strategy to learn about spirituality in occupational therapy education
}

\author{
T G Mthembu, ${ }^{1}$ BSc OT, MPH, PhD; A Rhoda, ${ }^{2}$ BSc PT, MSc, PhD \\ ${ }^{1}$ Department of Occupational Therapy, Faculty of Community and Health Sciences, University of the Western Cape, Cape Town, South Africa \\ ${ }^{2}$ Faculty of Community and Health Sciences, University of the Western Cape, Cape Town, South Africa
}

Corresponding author: T G Mthembu (tmthembu@uwc.ac.za)

\begin{abstract}
Background. A case study is a teaching strategy that is used in other professions, such as nursing and medicine; however, there are no studies that focus on the experiences of occupational therapy (OT) students regarding the use of a case study to learn about spirituality.

Objectives. To explore undergraduate OT students' experiences of using a case study as a teaching strategy to learn about spirituality.

Methods. Exploratory-descriptive qualitative research was conducted, using purposive sampling to select and recruit second-year OT students $(N=25)$ who consented to participate in the study. Transcribed data from three focus group discussions were thematically analysed through a credible process.

Results. Two major themes were identified. Theme 1, the importance of a case study as a teaching method, deals with students' learning experiences of using a case study. Theme 2, skills learnt through a case study, highlights profession-specific and academic skills that students managed to acquire and apply by using a case study as a learning strategy.

Conclusion. This study provided insight into the OT students' experiences of using a case study. The findings are consistent with previous research that focuses on the use of a case study as a teaching strategy, which enabled students to apply their knowledge in a real-life situation by recognising and solving problems through engaging in critical reflection and using various skills. This work contributes to existing knowledge of health sciences education by providing teaching and learning strategies that educators may use to facilitate students' engagement in collaborative learning.
\end{abstract}

Afr J Health Professions Educ 2021;13(2):96-98. https://doi.org/10.7196/AJHPE.2021.v13i2.1354

A case study is an innovative teaching and learning strategy that is grounded in case-based learning $(\mathrm{CBL}) \cdot{ }^{[1]} \mathrm{CBL}$ is a form of inquiry-based learning that fits on the continuum of structured and guided learning, which prepares students for clinical practice, using authentic clinical cases that mimic the real world. ${ }^{[2]}$ A systematic review indicated that case study is a teaching strategy that has been used to help students in nursing and medicine to learn about spirituality. ${ }^{\left[{ }^{3}\right]}$ However, there are no studies in occupational therapy (OT) education regarding the use of a case study. There is a need for research in the OT paradigm about the relevancy of a case study to enhance the holistic approach of body-mind-spirit. The requirements of a case study that helped the second-year OT students to apply their knowledge and skills throughout the semester of the OT and chronic diseases module are presented in Table 1.

\section{Methods}

Exploratory-descriptive qualitative research was conducted to explore OT students' experiences of using case study as a teaching strategy to learn about spirituality. The Kirkpatrick framework of evaluation of educational interventions related to perception, knowledge, skills, attitudes and behavioural changes guided the study. ${ }^{[4-6]}$ Purposive sampling with a maximum variation was used to recruit and select participants $(n=32)$, who were registered for a second-year OT module in 2018. Three research assistants simultaneously conducted and audiotaped three focus group discussions with only 25 second-year students, who consented to participate in the study. The students' responses related to the questions about their understanding of spirituality and experiences of using the case study were transcribed verbatim. ATLAS.ti8 Windows (ATLAS.ti, Germany) was used to thematically analyse the transcribed data through familiarisation, coding, refining and reviewing, and naming of the themes. This was a peer-examined process with an audit trail to enhance credibility and confirmability.

\section{Ethical approval}

Ethical approval was obtained from the University of the Western Cape Human and Social Science Research Ethics Committee (ref. no. HS18/4/5).

\section{Results and discussion \\ Theme 1: Importance of a case study}

The first theme contextualises the importance of a case study in facilitating learning among OT students' journey, which assisted them to learn about spirituality. The findings from the first theme corroborate with levels 1 and 2 of Kirkpatrick, which indicate that a case study provided the students with learning experiences for acquisition of concepts: ${ }^{[4,5]}$

'Spirituality is about connectedness with your surroundings even the people around you. I did not know that spirituality is like the internal part. If your spirit is positive, you are going to bring out that energy. It includes prayer that connects self with the greater Being. Now, I have the background of spirituality; I could see when we went to our client in Strand.'

'It [case study] really helps you to understand the bigger picture, and to look at every little aspect to form a conclusion based on assessing every little thing; it is an effective teaching method. 
Table 1. Requirements for a case study in occupational therapy and chronic diseases module

\section{Students expectations}

- Students were allocated to groups of 5 each and were expected to work together to design their case study, as part of sharing the workload

- Students were expected to apply the knowledge gained from classroom activities and a real-world situation

- Students had to identify and assess an older adult with chronic conditions (e.g. diabetes, hypertension, rheumatoid arthritis and amputation) using the World Health Organization International Classification of Functioning, Disability and Health to conceptualise a client in the community and design a case study

- Students had to give feedback on their progress and how they brainstorm regarding their case study

- Students had to access accredited journals in the library to search for articles related to their case study, and then summarise the literature in their own words

- Students were expected to use appropriate knowledge, research, referencing (mechanics) and peer feedback, digital and ethical reasoning, as well as quality of presentation (PowerPoint clear, not colour blind)

- Students were expected to prepare a presentation of their case study as part of their evaluation

- Students were expected to make recommendations for the clients' adaptations, which makes the students engage with older adults in the real world.

'It gives you a picture of the person rather than learning from a textbook that a client has this. It gives the person's image, not just what they do in everyday life but understanding of [what] the person believes; the person goes to church and pray. It helps us to understand the client on a spiritual level. It help us learn how we can adapt our intervention.'

'It also made me understand like what is happening in the real world rather than just reading it but actually going there asking questions.'

The students experienced a sense of belonging and becoming because they collaborated with each other as part of student-centred and peer learning, using available educational opportunities for teamwork. This finding corroborates with level 2 of Kirkpatrick, which highlights the importance of self-assessment, growth and self-efficiency: ${ }^{[4,5]}$

'When you are doing case studies you are in groups, you learn to like the opinions of others; you learn how to acknowledge their opinions, strengthens and your relationship with your colleagues because you need each other'

'I think that everything that you need is there, and you have resources around you, lecturer, friends and group so you can help yourself out if you are willing to try'.

'You learning everything for yourself to better your own knowledge.' 'I have realised that in group work you grow as a person because you learn about your strengths and weaknesses. There is a room to fix your work ethic and it helps with reflection.'

The students shared that they were able to use scaffolding strategies to dismantle a case study into manageable pieces, which enabled them to learn about the person-environment inter-relationship:

'By using case studies you learn the ability to break things down and interpret all the little pieces one by one, so you know like not just looking at it as like a big chunk of steak. You know, you cut the steak up and then you know it is easier to eat kind of a thing.'

'The part that helped me while in the community; we had to break down all the social injustices. Since we already learnt about social injustices so we could use our knowledge.'

'It was a good way for us to work in a group because we all came from different backgrounds like ethnically, racially and religiously everywhere from different backgrounds, it was a very good way to see things from a different perspective'

The findings in theme 1 further support level 3 of Kirkpatrick, which fostered behavioural changes among the students to apply their knowledge of social injustices while in community settings. ${ }^{[5]}$

\section{Theme 2: Skills learnt through a case study}

The second theme deals with profession-specific and academic skills that students learnt using a case study, which are substantiated by acquisition of Kirkpatrick level 2 skills. ${ }^{[4,5]}$ OT students gained profession-specific skills related to activity analysis and reflection:

'Case study is a little bit so you are breaking up your case into little pieces.

It makes it easier to see and it teaches new skills on how to do an activity analysis.'

'You actually reflect upon what you should have done and what you should do and what you shouldn't have done so I think that is where you better understand it based on the case study that was given.'

The students incorporated the gained educational skills related to information management and research as part of the case study to seek, discern and apply their knowledge in a real world:

'It encourages you to go find out information about the real world, you have to experience that and use literature and do research. I learned how to reference really well.'

The students gained confidence with personal skills (leadership, goal setting and creativity) that helped them to develop interpersonal interaction and flexibility, while solving complex problems with others:

'I had to take the lead and I had to do everything. It actually worked a lot by using time management as well and taking things step-by-step ... I learned how to delegate tasks and be able to trust people with something important, as my academics.'

'OT skills are like completely thinking out of the box you know and adapting yourself to a situation where you have no idea what to do ... there is no basis of understanding or anything. You are thrown into the deep end and you are afloat.'

'I learnt setting a goal by this day or that date, I want to accomplish this and you feel like you accomplished, and it actually boost your confidence.'

These findings support level 2 of Kirkpatrick and case-based learning because the students immersed themselves in their learning, which enabled them to gain more educational skills related to thinking/problem-solving and psychomotor and social skills if they are provided with learning opportunities. ${ }^{[1-8]}$ Overall, the findings of the current study indicate that students had a better understanding of spirituality as an internal energy that connects self with nature and others. The findings further show that the construction of a case study enabled the students' involvement, i.e. they 


\section{Short Report}

felt that they were involved in their learning and that they were part of the real world.

\section{Study limitations}

The results cannot be generalised to other professions or institutions, as they apply to OT students in an institution of higher learning.

\section{Conclusion}

The objective of this study was to explore OT students' experiences of using a case study as a teaching strategy to learn about spirituality. Based on the findings, it is clear that the use of case study helped them to learn about the importance of clients' spirituality and themselves as spiritual beings. Study results further indicated that the students achieved a variety of learning skills, including brainstorming, searching, reading and using the literature, researching and referencing, reflecting, scaffolding, collaborating and assessing.

\section{Declaration. None.}

Acknowledgements. We would like to thank the institution of higher learning for granting permission to conduct the study, the participants for sharing their experiences, the Sub-Saharan Africa-FAIMER Regional Institute (SAFRI) and the research assistants.
Author contributions. TGM conceptualised the study, applied for ethical clearance, reviewed the literature and wrote the methodology, results, discussion and conclusion. AR supervised and critically reviewed the article.

Funding. None.

Conflicts of interest. None.

1. Rybarczyk BJ, Baines AT, McVey M, Thompson JT, Wilkins H. A case-based approach increases student learnin outcomes and comprehension of cellular respiration concepts. Biochem Molec Biol Educ 2007:35(3):181-186. https://doi.org/10.1002/bmb.40

2. Thistlethwaite JE, Davies D, Ekeocha S, et al. The effectiveness of case based learning in health professional education. BEME guide number 23. Med Teach 2012;34(6):E421-E444. https://doi.org/10.3109/01421 9X.2012.680939

3. Mthembu TG, Wegner L, Roman NV. Teaching spirituality and spiritual care in health sciences education A systematic review. Afr J Physical Activity Health Sci 2016;22(4:1):1036-1057.

4. Kirkpatrick J, Kirkpatrick WK. The Kirkpatrick Four Levels ${ }^{\mathrm{TM}}$ : A fresh look after 50 years. 2009. https:/ openspaceconsulting.com/wp-content/uploads/2019/06/Kirkpatrick-Four-Levels-wp-updated.pdf (accessed 26 March 2020).

5. Hooper B, King R, Wood W, Bilics A, Gupta J. An international systematic mapping review of education approaches and teaching methods in occupational therapy. Br J Occup Ther 2013;76(1):9-22. https://doi.org/10.42 76\%2F030802213X13576469254612

6. Howe T, Sheu C, Hinojosa J. Teaching theory in occupational therapy using a cooperative learning: A mixedmethods study. J Allied Health 2018;47(1):66-71. https://doi.org/10.5014/ajot.2016.70S1-PO3020

7. Govender P, Mostert K. Making sense of knowing: Knowledge creation and translation in student occupation therapy practitioners. Afr J Health Professions Educ 2019;11(2):38-40. https://org/10.7196/AJHPE.2019. 1121123

8. Unin N, Bearing P. Brainstorming as a way to approach student-centered learning in ESL classroom. Procedia Social Behav Sci 2016;224:605-612. https://doi.org/10.1016/j.sbspro.2016.05.450

Accepted 17 August 2020 